\title{
(2) OPEN ACCESS \\ Future of global regulation of human genome editing: a South African perspective on the WHO Draft Governance Framework on Human Genome Editing
}

\author{
Bonginkosi Shozi (1) , Tamanda Kamwendo (ㄷ) , Julian Kinderlerer () , \\ Donrich W Thaldar 다, Beverley Townsend (ㄷ), Marietjie Botes
}

School of Law, University of KwaZulu-Natal, Durban, KwaZulu-Natal, South Africa

\section{Correspondence to} Bonginkosi Shozi, School of Law, University of KwaZulu-Natal, Durban 4041, KwaZulu-Natal, South Africa;

214511633@stu.ukzn.ac.za

Received 2 September 2020 Revised 28 January 2021 Accepted 5 February 2021
Check for updates

(C) Author(s) (or their employer(s)) 2021. Re-use permitted under CC BY-NC. No commercial re-use. See rights and permissions. Published by BMJ.

\begin{tabular}{l}
\hline To cite: Shozi B, \\
Kamwendo T, Kinderlerer J, \\
et al. J Med Ethics Epub \\
ahead of print: [please \\
include Day Month Year]. \\
doi:10.1136/ \\
medethics-2020-106863 \\
\hline
\end{tabular}

\section{ABSTRACT}

WHO in 2019 established the Advisory Committee on Developing Global Standards for Governance and Oversight of Human Genome Editing, which has recently published a Draft Governance Framework on Human Genome Editing. Although the Draft Framework is a good point of departure, there are four areas of concern: first, it does not sufficiently address issues related to establishing safety and efficacy. Second, issues that are a source of tension between global standard setting and state sovereignty need to be addressed in a more nuanced fashion. Third, it fails to meaningfully engage with the extent to which the conceptualisation of human dignity may justifiably vary between jurisdictions. Fourth, the meaning of harm to the interests of a future person requires clarity. Provided these four areas of concern can be addressed, the future of the global governance of human genome editing may hold promise.

\section{INTRODUCTION}

The prospect of editing the human genome using CRISPR-Cas9 (and updated precision technologies) has increasingly become a point of contention in global bioethics. In particular, there continues to be considerable disagreement on the question of if, and under what circumstances, making heritable changes to the human genome is acceptable. ${ }^{1}$ Within this debate, there have emerged voices that argue that, because of the potentially global impacts of human genome editing, this is not the kind of issue that can be left to the discretion of individual states or ethics committees, but rather requires a coordinated global response in the form of a treaty, a moratorium or a 'boycott'. ${ }^{3}$ Such mechanisms have invited a measure of scepticism for a number of reasons-most notably, because of questions about their viability. ${ }^{4}$ The current pandemic, and the extremely partisan acting of major global powers like the USA on issues such as the stockpiling of vaccine candidates, ${ }^{5}$ illustrates quite clearly that the probability of world-wide agreement on the regulation of genome editing seems unlikely.

Does this mean that there is no hope for any sort of global regulatory mechanism for human genome editing? Perhaps not. WHO in 2019 established the Advisory Committee on Developing Global Standards for Governance and Oversight of Human Genome Editing, with the task to 'advise and make recommendations on appropriate institutional, national, regional and global governance mechanisms for human genome editing' ${ }^{6}$ Given the widely respected status of the WHO as an institution, they potentially have the influence and infrastructure required to undertake an endeavour as ambitious as a global standard policy for human genome editing. Pursuant to consultation with its members, individual experts and members of the public, including representatives of marginalised groups, the Committee has recently released for comment a Draft Governance Framework on Human Genome Editing. ${ }^{7}$ The Draft Framework provides a first glimpse at the potential future of the global regulation of human genome editing.

The Draft Framework is divided into five parts. Part 1 addresses the challenges associated with human genome editing, bearing in mind its scientific potential and giving a concise overview of ethical concerns. Part 2 speaks to the need to establish global baseline standards while acknowledging that different regulatory approaches may be required taking into account that the harm-benefit analysis varies across jurisdictions. Part 3 proposes values and principles such as human dignity, which ought to be taken into consideration in regulating human genome editing. Part 4 acknowledges existing infrastructure, including institutions and civil society, which would need to be leveraged to facilitate the establishment of global standards. Part 5 recognises that human genome editing may be applied in a wide range of settings, including heritable genome editing, and thus sets out different scenarios-with the aim of illustrating how the principles outlined under part 3 conjoin.

In our view, the setting of global benchmarks through the development of governance frameworks is both viable and necessary. However, when doing so, it is paramount that such frameworks strike a balance between providing substantive guidance for safeguarding health and safety at the international level, and giving states the freedom necessary to determine their positions on issues that turn on contextually specific factors, such as the meaning of principles and values. In this light, we suggest that the Draft Framework is a good point of departure, but it presents distinct areas of concern, relating to: (1) safety standards, (2) the global-versus-national dynamic, (3) human dignity and (4) harm to future persons. In the sections below, we analyse these four areas of concern in more detail. Given that the most contentious issue in the context of human genome editing is heritable genome editing, this will be the focus of our analysis. 


\section{ESTABLISHING A GLOBAL STANDARD OF SAFETY}

One of the most pivotal issues motivating the need for global governance of heritable genome editing, is the necessity of avoiding premature ventures into human applications. When considering the safety of any editing of the human genome, the Draft Framework notes that all medical interventions carry a risk to individuals. The question then becomes 'what is safe enough?' In most instances the impact of medical interventions affects only the individual undergoing such intervention, although there are many instances of medication having unwanted effects on future generations (eg, thalidomide). However, heritable genome editing carries risks for both the child born and its progeny. Parents at risk of having a child that carries a heritable disease that could theoretically be cured using heritable gene editing may well be willing to take significant risks. Should they be the only arbiters, or should society dictate the conditions under which particular interventions are to be available? The contrary scenario may also become reality, where society encourages particular interventions. Societies that suffer from a high disease burden may in future view heritable genome editing as a desirable public health solution-provided, of course that: (1) heritable genome editing can in fact be used to make a new generation immune against the disease(s) and that (2) there is an easy to use and affordable delivery mechanism.

The possibility that different standards for safety are used in different jurisdictions opens the probability of medical tourism for those with the means, with failures then impacting on the health services in other countries. On the other hand, societal acceptance of risk differs in different societies, and it may be that a technology rejected by some for legitimate safety concerns, may be acceptable in another jurisdiction. The risk, however, is that of some countries setting the bar of safety lower than is reasonably justifiable. Thus, the final Framework must speak to the questions that arise in determining the safety of germline interventions, and provide guidance on issues of global significance such as how preclinical research and clinical trials for heritable gene editing should be conducted, ${ }^{8}$ and the viability of intergenerational monitoring. ${ }^{9}$

The challenges in determining global benchmarks for safety and efficacy speak to a deeper challenge, which is central to the establishment of a global framework that merits further examination.

\section{BALANCING GLOBAL STANDARDS AND STATE SOVEREIGNTY}

Principles or core values might provide a shared form of reference, which in turn encourages cooperation and harmonisation between countries. ${ }^{10}$ These principles may then form the corpus of moral standards that can be applied to health issues that are characterised by the need for a global, coordinated effort. ${ }^{11} 12$ However, in doing so, it is important to be respectful of, and sensitive to, a state's sovereignty.

That public acceptance and state policy will vary among countries and lead to divergent policy responses, is quite correctly anticipated. ${ }^{13}$ As the values of society reflect a particular time, location and context, certain countries may well be slower to (or resist) the implementation of regulatory measures, or their laws may simply be silent on matters governing such technologies. However, the Draft Framework cautions against human genome editing 'travel or tourism' and suggests that measures be taken to prohibit and deter such activities.

Even if it is reasonable to expect that disparities in the approaches taken by various states to regulating human genome editing might result in people travelling to countries with more permissive regulation to access this technology, it does not follow that 'medical tourism' is morally indefensible - and thus, it does not follow that it ought to be prohibited. The final Framework ought to acknowledge that therapies are frequently sought by people who are denied access to therapies for reasons such as high healthcare costs, long waiting periods or even the prohibition of access to novel or advanced therapies. ${ }^{14}$

From the perspective of individual states, if regulated constructively, medical tourism can be used to improve the professional exposure of locally qualified medical practitioners, and allow genetic engineers and biomedical specialists the opportunity to develop and refine their skills in respect of advanced medicines and therapies at competitive salaries. ${ }^{15}$ As such, states may have defensible reasons for adopting permissive policies, and should not be seen by the global community as acting in bad faith.

Permissive positions may, for instance, be justified on the basis of varying interpretations on widely accepted principles or concepts-as we discuss below.

\section{DIGNITY AND AUTONOMY}

In its discussion of human dignity, the Draft Framework routinely refers to human dignity in reference to the need to protect against 'causing harm'-either to individuals now, living or those yet to be born. In other words, the report seems to view human dignity as a basis for a constraint on the use of genome editing technologies.

Human dignity is a famously nebulous concept, whose meaning varies significantly depending on the context within which it is used. ${ }^{16}$ The view of human dignity that is represented in the Draft Framework represents what Beyleveld and Brownsword term human dignity as constraint ${ }^{16}$ - a view of human dignity which has been prominent in both international human rights and bioethics, a phenomenon attributed to be a product of the extent to which each of these spheres is heavily influenced by Eurocentric paradigms. ${ }^{17} 18$ This may be best observed in the following passage in 3.1 , which speaks directly to heritable genome editing:

'Heritable human genome editing, if approved for research and clinical applications, raises concerns with regard to fairness, social justice and non-discrimination, as well as potential disregard for the individual dignity of persons with disabilities.'

While the report does well to acknowledge concerns often raised by advocates for persons with a disability, it is important to note that these claims are based on a particular conceptualisation of human dignity. In terms of this view, 'human dignity' can be infringed on in the abstract by acts that do not directly affect a particular person. This is a departure from the general view of human rights as only being capable of being infringed where a particular rights-holder's interests are affected. This view of human dignity is far from universal, and has in fact been heavily critiqued for, inter alia, framing human dignity in terms which permit arbitrary deprivations of autonomy. ${ }^{19}$

By contrast, in many jurisdictions human dignity is associated less with dignity as constraint, and more with what Beyleveld and Brownsword term dignity as empowerment. An example of this is South Africa, where human dignity has been closely associated with autonomy by the constitutional court. ${ }^{20}$ Viewed in this way, a prohibition on heritable genome editing raises concerns of failing to respect the human dignity of those persons who would freely and autonomously choose to use this technology. This is problematic insofar as it is arguably a violation of the freedom of 
individuals to make decisions in matters of procreation-a right which is well entrenched in international human rights documents, and the jurisprudence of liberal democracies. ${ }^{21}$ In this context, it is also important to note that there may be morally defensible reasons for choosing to use human genome editing technology, such as to avoid heritable disease in a way that does not require the destruction of unused embryos. ${ }^{22}$

For these reasons, we recommend that the final Framework should more clearly recognise that the concept 'human dignity' is subject to more than one interpretation, and explicitly consider the policy implications of not only dignity as restraint, but also of dignity as empowerment.

We also recommend that the regulation of heritable genome editing - at least in states committed to upholding human rights and the fundamental freedoms of individuals - should follow the principle: Respect parents' reproductive autonomy. ${ }^{22}$ The advancement of this principle does not mean that parental choice should go unchecked, as this may lead to problematic outcomes such as parents selecting for genes which cause their children to endure significant hardship in life. Rather, it means that parents should be seen as having the freedom to make choices regarding if, when and how to use genome editing technology, unless there are logically sound and evidence-based justifications for their choices to be limited.

\section{WHAT DOES 'HARM' TO THE PROSPECTIVE PERSON REALLY MEAN?}

Under the heading 'respect for individual dignity', the Draft Framework repeats the statement that there is a 'particular need to protect the interests of future persons'. The Draft Framework assumes that the interests of future persons fall within the meaning of 'respect for individual dignity'. But what exactly is a 'future person'? Does it refer to the embryo? And how can the future persons interests be set back (ie, harmed) by heritable genome editing, if they do not exist at the time the edits are made?

The Draft Framework seemingly avoids taking a position on the embryo per se, and rather focuses on protecting the interests of the 'future person' (which we term the 'prospective person' or 'prospective child'). Depending on one's view of the moral status of the embryo, (1) the embryo might already be the prospective person, or (2) the embryo might only be the human biological material that might, in future, give rise to the prospective person. Although views on this vary, the idea of protecting the interests of the prospective person is a principle around which international consensus can be built. For those who adhere to a strict version of (1), this would mean protecting the interests of an embryo; for those who adhere to (2) - the position in South African law ${ }^{23}$ - protecting the interests of the future person does not imply that embryos have any interests.

But is it possible to harm the interests of a prospective person as per (2), where the prospective person is something intangible, which exists only in our minds? We suggest the answer is yes. In fact, the South African courts do so on a routine basis: Every time that a court is seized with a surrogate motherhood agreement confirmation application, the court must consider the interests of the child to be born or the prospective person. ${ }^{24}$ This is based on the common sense premise that acts in the present and can have consequences in the future for persons who do not yet exist. Accordingly, an edit to an in vitro embryo can affect the rights or interests of the prospective person if, and only if, that embryo is destined to be used for reproductive purposes. In other words, an edit to the embryo (the human biological material that may give rise to a person) takes place before the existence of the prospective person, but it can impact their interests after they come into existence-either in a beneficial way, or in a harmful way, depending on the nature of the change.

Although the Draft Framework alludes to potential harms and benefits to the genetically modified prospective person, the reference to benefits is supported with an example that can be read as implying adherence to conception (1), namely the benefit in existence. If an embryo is deemed to have interests, existence would probably be a foundational interest. However, if one adheres to conception (2), citing existence as a benefit does not make much sense: When the interests of the future person are considered in conception (2), the future existence of the future person is the hypothetical condition that underlies the thought experiment, rather than a benefit. A benefit according to both conceptions (1) and (2) would be something such as immunity against a deadly disease. The final Framework should be explicit about these possible benefits of heritable genome editing that are inclusive of conceptions (1) and (2).

When would a specific heritable genome edit amount to a harm? Given that harm already plays an important role both in criminal law and in the law of civil wrongs (delict or tort), it would be internally consistent and aid legal certainty for each jurisdiction to simply expand its existing legal rules to this new frontier of genome editing. In this regard, the following test for harm has been suggested ${ }^{24}$ :

'If a reproductive decision by a prospective parent is likely to have an effect on the prospective child that would constitute either a civil or criminal wrong in law if caused by an act by a parent toward an existing child, such reproductive decision would constitute harm to the prospective child.'

This test for harm offers at least two benefits: first, it avoids the ethical debates about the meaning of harm by respecting the sovereignty of each state to apply its own existing legal conception of harm-as developed and understood against the background of its own culture and history. Second, since it uses the concept of the prospective child (or future person), it respects the sovereignty of each state to decide on the moral status of the embryo, and accommodates both conceptions (1) and (2) set out above. Accordingly, we recommend that this test for harm be incorporated in the final Framework.

\section{CONCLUSION}

The committee has done a commendable job in approaching the various ethical, social and legal issues that are raised by human genome editing. This is, indeed, a positive step in the direction of establishing a global framework on the regulation of human genome editing, which creates well founded baselines on which states can develop policy that fits within their particular jurisdiction. Yet, we have highlighted four areas of concern that deserve attention. If these four areas of concern can be successfully addressed in the final Framework, the future of the global governance of human genome editing may hold promise.

Contributors BS, TK, JK, DWT, MB and BT are coauthors of this manuscript, and reviewed and approved the manuscript prior to submission.

Funding This article is based on research supported by the National Research Foundation of South Africa (grant number: 116275) and by the African Health Research Flagship of the University of KwaZulu-Natal.

Competing interests None declared.

Patient consent for publication Not required. 
Provenance and peer review Not commissioned; externally peer reviewed.

Data availability statement There are no data in this work.

Open access This is an open access article distributed in accordance with the Creative Commons Attribution Non Commercial (CC BY-NC 4.0) license, which permits others to distribute, remix, adapt, build upon this work non-commercially, and license their derivative works on different terms, provided the original work is properly cited, appropriate credit is given, any changes made indicated, and the use is non-commercial. See: http://creativecommons.org/licenses/by-nc/4.0/.

\section{ORCID iDs}

Bonginkosi Shozi http://orcid.org/0000-0003-2994-0795

Tamanda Kamwendo http://orcid.org/0000-0002-5434-113X

Julian Kinderlerer http://orcid.org/0000-0003-0481-0441

Donrich W Thaldar http://orcid.org/0000-0002-7346-3490

Beverley Townsend http://orcid.org/0000-0002-8486-6041

Marietjie Botes http://orcid.org/0000-0002-6613-6977

\section{REFERENCES}

1 Shozi B. A critical review of the ethical and legal issues in human germline gene editing: considering human rights and a call for an African perspective. South Afr J Bioeth Law 2020;13:62-7.

2 Lander ES, Baylis F, Zhang F, et al. Adopt a moratorium on heritable genome editing. Nature 2019;567(7747):165-8.

3 Hough SH, Ajetunmobi A. A CRISPR Moratorium Isn't Enough: We Need a Boycott. Crispr J 2019:2(6):343-5.

4 Macintosh KL. Heritable genome editing and the downsides of a global moratorium. Crispr J 2019;2(5):272-9.

5 U.S. to stockpile vaccine candidates as trials continue: health Secretary. Reuters, 2020. Available: https://www.reuters.com/article/us-health-coronavirus-usa-vaccineidUSKBN22R2C0 [Accessed 10 Aug 2020].

6 Advisory Committee on developing global standards for governance and oversight of human genome editing. Report of the first meeting, 2019. Available: https://www. who.int/ethics/topics/human-genome-editing/GenomeEditing-FirstMeetingReportFINAL.pdf?ua= 1 [Accessed 25 Aug 2019].

7 Who Advisory Committee on developing global standards for governance and oversight of human genome editing. human genome editing: a draft framework for governance, 2020. Available: https://www.who.int/docs/default-source/ethics/ governance-framework-for-human-genome-editing-2ndonlineconsult.pdf?ua=1 [Accessed 2 Aug 2020].

8 Nordgren A. Designing preclinical studies in germline gene editing: scientific and ethical aspects. J Bioeth Inq 2019;16(4):559-70.

9 Cwik B. Intergenerational monitoring in clinical trials of germline gene editing. J Med Ethics 2020:46(3):183-7.

10 Dove ES, Knoppers BM, Zawati Ma'n H. Towards an ethics safe harbor for global biomedical research. J Law Biosci 2014;1:3-51.

11 Stapleton G, Schröder-Bäck P, Laaser U, et al. Global health ethics: an introduction to prominent theories and relevant topics. Glob Health Action 2014;7:23569.

12 Townsend BA. Human genome editing: how to prevent rogue actors. BMC Med Ethics 2020:21(1):95.

13 National Academies of Sciences E. Second International Summit on human genome editing: continuing the global discussion: proceedings of a Workshop-in brief, 2019. Available: https://www.nap.edu/catalog/25343/second-international-summit-onhuman-genome-editing-continuing-the-global-discussion

14 Horowitz MD, Rosensweig JA, Jones CA. Medical tourism: globalization of the healthcare marketplace. MedGenMed 2007;9(4).

15 Cortez N. Patients without borders: the emerging global market for patients and the evolution of modern health care. Indiana law journal 2008;83.

16 Beyleveld D, Brownsword R. Human dignity, human rights, and human genetics. Mod Law Rev 1998:61(5):661-80.

17 McCrudden C. Human dignity and judicial interpretation of human rights. Eur J Int Law 2008;19(4):655-724.

18 Łuków P. A difficult legacy: human dignity as the founding value of human rights. Hum Rights Rev 2018;19(3):313-29.

19 Jordaan D, research Scell. Stem cell research, morality, and law: an analysis of Brüstle v Greenpeace from a South African perspective. S Afr J Hum Rights 2017;33(3):429-51.

20 Jordaan DW, University of Miami / Georgia Tech. Autonomy as an element of human dignity in South African case law. J Philos Sci Law 2009;9(3):1-15.

21 Shozi B, old S. Something old, something new: applying reproductive rights to new reproductive technologies in South Africa. S Afr J Hum Rights 2020:36(1):1-24.

22 Thaldar D, Botes M, Shozi B. Human germline editing: Legal-ethical guidelines for South Africa. South Afr J Sci 2020;116.

23 Ex Parte KAF [2018] ZAGPJHC 529, 2019 (2) SA 510 (GJ). Available: http://www. saflii.org/za/cases/ZAGPJHC/2018/529.html [Accessed 13 Aug 2020].

24 Thaldar D, Shozi B. Procreative Non-Maleficence: a South African human rights perspective on heritable human genome editing. Crispr J 2020;3(1):32-6. 